\title{
The Dependence of Daily and Hourly Precipitation Extremes on Temperature and Atmospheric Humidity over China ${ }^{\mathscr{O}}$
}

\author{
HONG WANG \\ Key Laboratory of Water Cycle and Related Land Surface Processes, Institute of Geographic Sciences and \\ Natural Resources Research, Chinese Academy of Sciences, Beijing, China
}

\section{FUBAO SUN}

Key Laboratory of Water Cycle and Related Land Surface Processes, Institute of Geographic Sciences and Natural Resources Research, Chinese Academy of Sciences, Beijing, and Research School of Qilian Mountain Ecology, Hexi University, Zhangye City, and College of Resources and Environment, University of Chinese Academy of Sciences, and Center for Water Resources Research, Chinese Academy of Sciences, Beijing, China

\section{WENBIN LIU}

Key Laboratory of Water Cycle and Related Land Surface Processes, Institute of Geographic Sciences and Natural Resources Research, Chinese Academy of Sciences, Beijing, China

(Manuscript received 30 January 2018, in final form 9 August 2018)

\begin{abstract}
Precipitation extremes are expected to increase by $7 \%$ per degree of warming according to the ClausiusClapeyron (CC) relation. However, this scaling behavior is inappropriate for high temperatures and shortduration precipitation extremes. Here, daily data from 702 stations during 1951-2014 and hourly data from 8 stations during 2000-15 are used to examine and explain this behavior in China. Both daily and hourly precipitation extremes exhibit an increase in temperature dependency at lower temperatures. The CC scaling transitions from positive to negative rates with temperatures greater than $25^{\circ} \mathrm{C}$. Unlike the increase in daily data, which is similar to single-CC $(1 \mathrm{CC})$ scaling, the increase in hourly data resembles super-CC (2CC) scaling for temperatures greater than $13^{\circ} \mathrm{C}$. Results show that the precipitation extremes are controlled by water vapor for a given temperature. At lower temperatures, precipitation extremes exhibit a positive linear dependence on daily actual vapor pressure whose value is almost equal to the saturated vapor pressure at a given temperature. At higher temperatures, actual vapor pressure has difficulty maintaining a consistent increasing rate because of the exponential increasing of the saturated vapor pressure. Higher temperatures result in larger vapor pressure deficits, which lead to sharp decreases in precipitation extremes. Similar scaling behaviors are obtained in 10 river basins over China, where the breaking point temperature increases from $17^{\circ} \mathrm{C}$ along the northwest inland area to $25^{\circ} \mathrm{C}$ along the southeast coast. These behaviors demonstrate that precipitation extremes are firmly linked to temperature when there is sufficient moisture at lower temperatures and limited by insufficient moisture at higher temperatures. Overall, precipitation extreme events require more attention in a warming climate.
\end{abstract}

\section{Introduction}

Evidence that precipitation extremes are increasing globally has strengthened considerably in recent years (Berg et al. 2013; Fischer and Knutti 2016;

Supplemental information related to this paper is available at the Journals Online website: https://doi.org/10.1175/ JCLI-D-18-0050.s1.

Corresponding author: Fubao Sun, sunfb@igsnrr.ac.cn
Lenderink and Meijgaard 2008; Westra et al. 2014). Precipitation extremes are expected to increase by $7 \%$ per degree of warming according to the ClausiusClapeyron (CC) relation, which states that the atmosphere can hold approximately $6 \%-7 \%$ more water vapor per degree of warming before saturation occurs (Lenderink and Meijgaard 2008; Trenberth et al. 2003). However, this scaling behavior does not appear to be appropriate for high temperatures (Busuioc et al. 2017; Chan et al. 2016; Drobinski et al. 2016; Wang et al. 2017) and short-duration precipitation extremes 
(Haerter and Berg 2009; Jones et al. 2010; Lenderink and Meijgaard 2008).

Negative scaling behaviors because of high temperatures for both daily and subdaily precipitation extremes have been found in the Amazon and Congo basins, the tropical Pacific, the Indian monsoon region, the U.S. Midwest, central Europe (Wang et al. 2017), Romania (Busuioc et al. 2017), the United Kingdom (Chan et al. 2016), the Mediterranean (Drobinski et al. 2016), Australia (Jones et al. 2010), Japan (Utsumi et al. 2011), South Korea (Park and Min 2017), and China (Huang et al. 2017; Sun et al. 2013; Xiao et al. 2016). Additionally, the breaking point temperature (the temperature for the $\mathrm{CC}$ scaling transition from positive to negative rates) has been found to be different in different study areas, and it is $\sim 22^{\circ} \mathrm{C}$ in the United Kingdom (Chan et al. 2016), $20^{\circ} \mathrm{C}$ in the Mediterranean (Drobinski et al. 2016), $26^{\circ} \mathrm{C}$ in Australia (Jones et al. 2010), $\sim 20^{\circ}-24^{\circ} \mathrm{C}$ in southeastern Austria (Schroeer and Kirchengast 2018), $25^{\circ} \mathrm{C}$ in China (Huang et al. 2017; Sun et al. 2013; Xiao et al. 2016), and $18^{\circ} \mathrm{C}$ during spring and summer at the 99.9 th percentile in Romania (Busuioc et al. 2017). Short-duration precipitation extremes have exceeded CC relation expectations, and a transitional behavior from single-CC (1CC) to super-CC (2CC) scaling for hourly precipitation extremes has been found (Haerter and Berg 2009; Lenderink and Meijgaard 2008). Station observations suggested that 1-h precipitation extremes increase twice as fast with rising temperatures, as expected from the $1 \mathrm{CC}$ relation, when daily mean temperatures exceed $12^{\circ} \mathrm{C}$ (Haerter and Berg 2009; Lenderink and Meijgaard 2008).

Model predictions have shown that future daily precipitation extremes will continue to intensify (Donat et al. 2016), and the observed scaling rates of precipitation extremes are found to be larger than that predicted by models, implying that future changes in precipitation extremes may still be underestimated (Allan and Soden 2008) because of the change in water vapor (Bao et al. 2017). Barbero et al. (2017) have suggested that it may be helpful to determine whether or not future changes in precipitation extremes are likely to exceed observed scaling rates that are estimated using dewpoint temperature variations rather than surface temperature. Future hourly precipitation extremes cannot simply be extrapolated from daily precipitation extremes scaling analyses, and the models cannot provide a reliable extrapolation basis until improved methods are available (Chan et al. 2016; Zhang et al. 2017).

Atmospheric humidity, precipitation type and duration, microphysics, El Niño events, orography, anthropogenic aerosols, and greenhouse gases have been thought to influence the scaling behaviors of precipitation extremes at higher temperatures or for short durations. First, atmospheric moisture availability with increasing temperatures has been identified as a particularly large influence on scaling. The increase in daily precipitation intensity has also been strongly associated with the increase in water vapor (Ye et al. 2015). Both observations and models show a strong reduction in relative humidity at higher temperatures, which reflects how moisture availability becomes the dominant driver in extreme precipitation events (Jones et al. 2010; Sun et al. 2015; Xiao et al. 2016). Several results have shown that the dewpoint temperature has been used as an alternative measure with which to investigate the combined effect of atmospheric temperature and moisture availability that drives precipitation extremes (Barbero et al. 2017; Westra et al. 2014). Trenberth et al. (2003) have argued that because heavy rainfall rates greatly exceed evaporation rates and thus depend on low-level moisture convergence, the rainfall intensity should also increase at about the same rate as the moisture increases, namely, $7 \% \mathrm{~K}^{-1}$ with warming. In fact, the rate of increase can even exceed this because the additional latent heat released feeds back and invigorates the storm that causes the rain in the first place, further enhancing convergence of moisture (Trenberth et al. 2003; Liu et al. 2009). Therefore, precipitation extremes increase with temperature in moist, energy-limited environments and decrease abruptly in dry, moisturelimited environments (Prein et al. 2017). Second, precipitation can be separated into convective and stratiform events based on cloud observations (Berg et al. 2013) or the presence of lightning (Molnar et al. 2015). Convective precipitation has a more sensitive response to temperature increases than that from stratiform precipitation, which has increasingly dominated subdaily precipitation extremes (Berg et al. 2013; Busuioc et al. 2017; Molnar et al. 2015; Singleton and Toumi 2013) because of the increased propagation of squall lines (Singleton and Toumi 2013); these events exhibit typical convective precipitation structures, which scaling breaks down at higher temperatures (Singleton and Toumi 2013). And results of models and simulations also imply that the convective systems drive precipitation extremes (Meredith et al. 2015; Moseley et al. 2016). Other results have shown that $\mathrm{CC}$ scaling is also mainly dependent on precipitation duration (Utsumi et al. 2011; Sun et al. 2013), cloud and precipitation microphysics (Singh and O'Gorman 2014), El Niño events (Allen and Luptowitz 2017), orography (Drobinski et al. 2016), and anthropogenic aerosols and greenhouse gases (Chen et al. 2011; Min et al. 2011).

Intense precipitation extreme events create complex processes and involve multiple factors, which makes it challenging to examine and explain their behaviors, especially for China. Research in this area is quite poor and China includes many climatic regions, which makes the problem even more complicated. Here, we used 

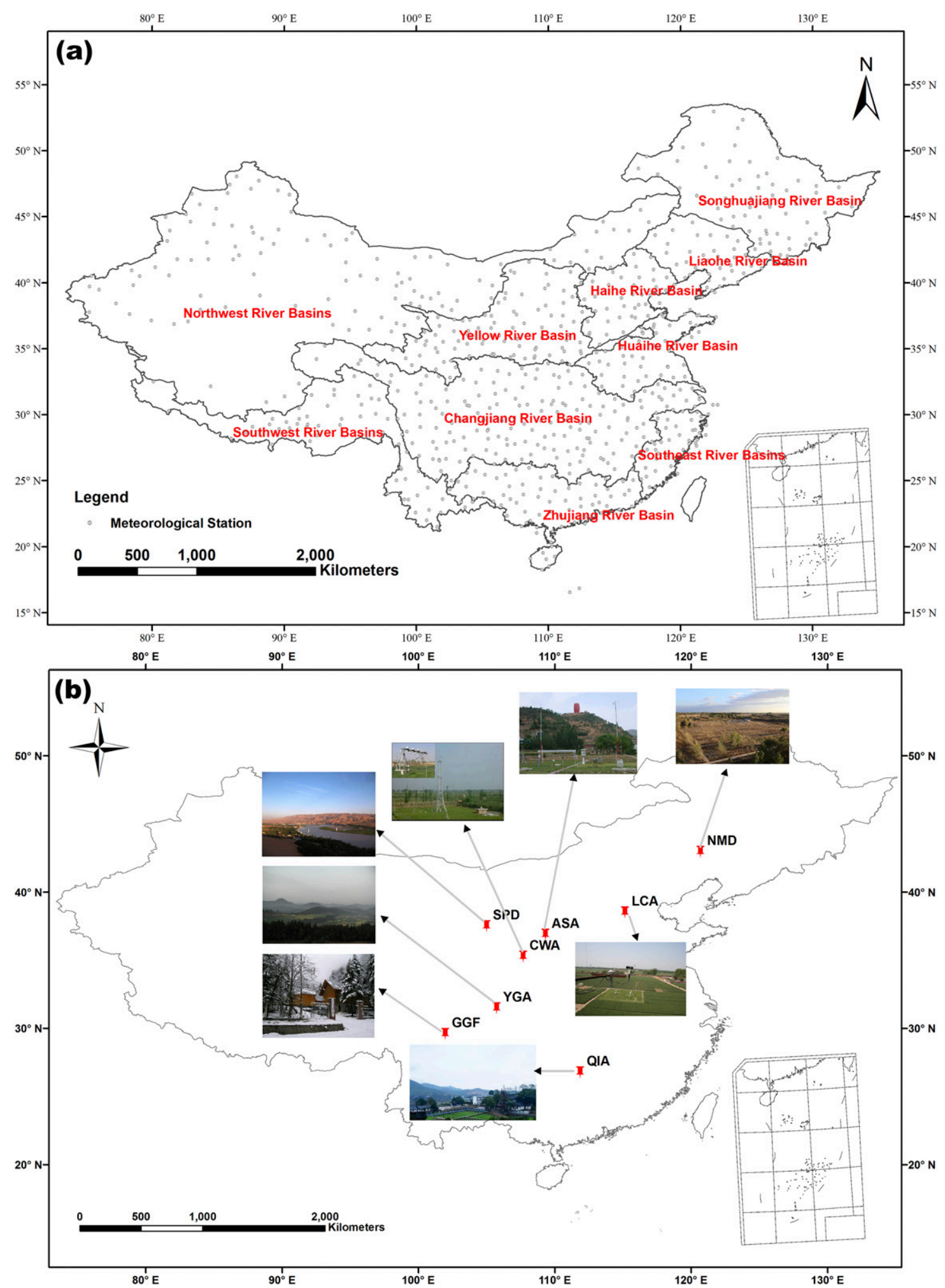

FIG. 1. The locations of meteorological stations. (a) Daily meteorological stations and 10 river basins over China. (b) Hourly meteorological stations, including ASA, CWA, LCA, YGA, NMD, SPD, GGF, and QIA. 
TABLE 1 . The information of the daily database and its precipitation events.

\begin{tabular}{lclll}
\hline & \multicolumn{2}{c}{ Database } & & Data of precipitation events \\
\hline Mean temperature & $>25^{\circ} \mathrm{C}$ & $<0^{\circ} \mathrm{C}$ & Proportion & Mean temperature \\
$11.58^{\circ} \mathrm{C}$ & $13.64 \%$ & $17.60 \%$ & $29.28 \%$ & $15.47^{\circ} \mathrm{C}$ \\
\hline
\end{tabular}

temperature, precipitation, and water-vapor-related variables [actual vapor pressure $e_{a}$, specific humidity $q$, relative humidity $(\mathrm{Rh})$, and pan evaporation $\left.E_{\mathrm{pan}}\right]$ to study the dependence of daily and hourly precipitation extremes on temperature and atmospheric humidity over China. In section 2, we describe the data and methods. Section 3 reports the results of the relationship between temperature and precipitation extremes and attempts to explain the results quantitatively, which is then followed by the conclusion. The abbreviation of variables in the manuscript is shown in the appendix.

\section{Data and methods}

Figure 1 shows the spatial locations of the meteorological stations. Figure 1a shows the daily data stations and 10 river basins in China. Figure $1 \mathrm{~b}$ shows the hourly data stations. The daily surface data during 1951-2014 are obtained from 702 meteorological stations associated with the China Meteorological Data Service Center (CMDC; http://data.cma.cn; Fig. 1a). The data have been strictly quality controlled (CMDC 2012) and contain approximately 6325552 data points. Daily precipitation amounts larger than $0.1 \mathrm{~mm} \mathrm{day}^{-1}$ are defined as precipitation events. The information of the daily database and its precipitation events is shown in Table 1. The $E_{\mathrm{pan}}$ is observed by a D20 pan (i.e., an evaporative pan), which has a $20-\mathrm{cm}$ diameter and $10-\mathrm{cm}$-high walls.

Hourly surface data from 2000 to 2015 are obtained by eight field experiments and monitoring stations (Fig. 1b), including Ansai (ASA), Changwu (CWA), Luancheng (LCA), Yanting (YGA), Naiman (NMD), Shapotou (SPD), Gongga Shan (GGF), and Qiyang (QIA), China, which are provided by the Chinese Ecosystem Research Network (CERN; http://www.cnern.org.cn) and support ecological-, climatic-, and agricultural-related research (Wang et al. 2016; Lu et al. 2016; Zhang et al. 2016). The data are measured hourly with the Milos 520 data collection and processing system, which is an automatic weather station produced by the Vaisala Company (Finland) and has field-proven reliability and accuracy (http://www.vaisala.com/en/Pages/ default.aspx). The data have been strictly quality controlled and contain approximately 592841 data points, of which $6.38 \%$ have intensities greater than $0.1 \mathrm{~mm} \mathrm{~h}^{-1}$.

Here, we reproduce the $\mathrm{CC}$ scaling method using the Lenderink and Meijgaard (2008) methodology. Daily precipitation intensity $I_{d}$ is binned using daily mean temperature at 2-m height $T$, and hourly precipitation intensity $I_{h}$ and $q$ are binned using $T_{d}$ or the hourly mean temperature at $2-\mathrm{m} T_{h}$, where the width of each bin is $2^{\circ} \mathrm{C}$. Wet events are defined by hours with precipitation values $>0.1 \mathrm{~mm} \mathrm{~h}^{-1}$. The 90th confidence intervals are estimated by the bootstrap method. The 99.9th, 99th, 95th, 90th, and 75th percentiles computed from the raw data falling within the confidence interval are estimated from the bootstrap method, where the bootstrap results are based on 1000 bootstrap samples using the International Business Machines Corporation (IBM) Statistical Product and Service Solutions (SPSS) Statistics, version 22.0. The hourly $q$ is calculated from the hourly $e_{a}$ and atmospheric pressure at each station (Ye et al. 2015).

\section{Results and discussion}

a. The dependence of daily precipitation extremes on temperature and atmospheric humidity

\section{1) THE RELATIONSHIP BETWEEN DAILY PRECIPITATION EXTREMES AND TEMPERATURE}

Figure 2 shows the 99.9th, 99th, 95th, 90th, and 75th percentiles of daily precipitation intensity $I_{d}$ compared with the CC relation. Different percentiles of $I_{d}$ exhibit

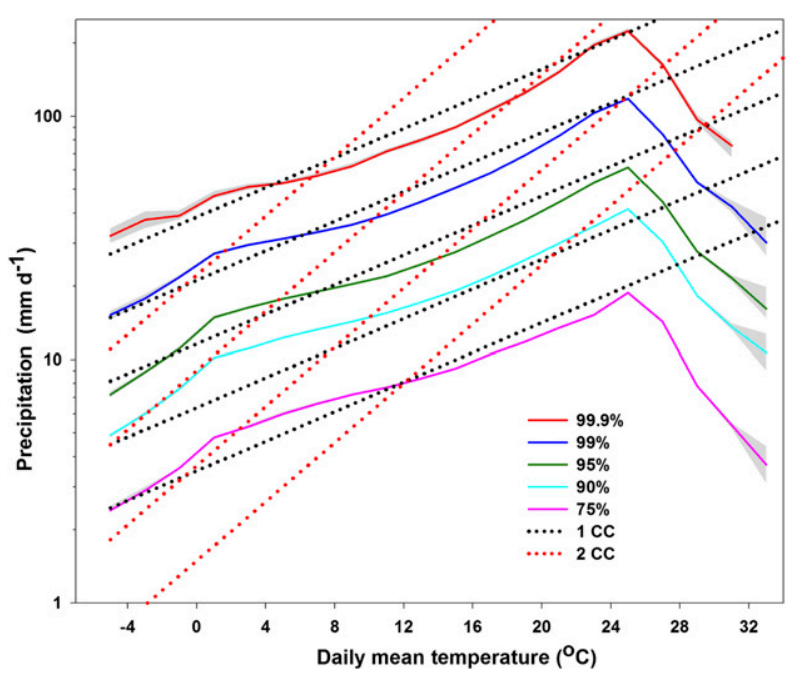

FIG. 2. Daily precipitation intensity $I_{d}$ dependence on $T$. Solid color lines represent the 99.9th, 99th, 95th, 90th, and 75th percentiles. Gray bands represent the 90 th percentile confidence intervals estimated by the bootstrap method. Dotted lines represent the 1CC (black) and 2CC (red) relations. 

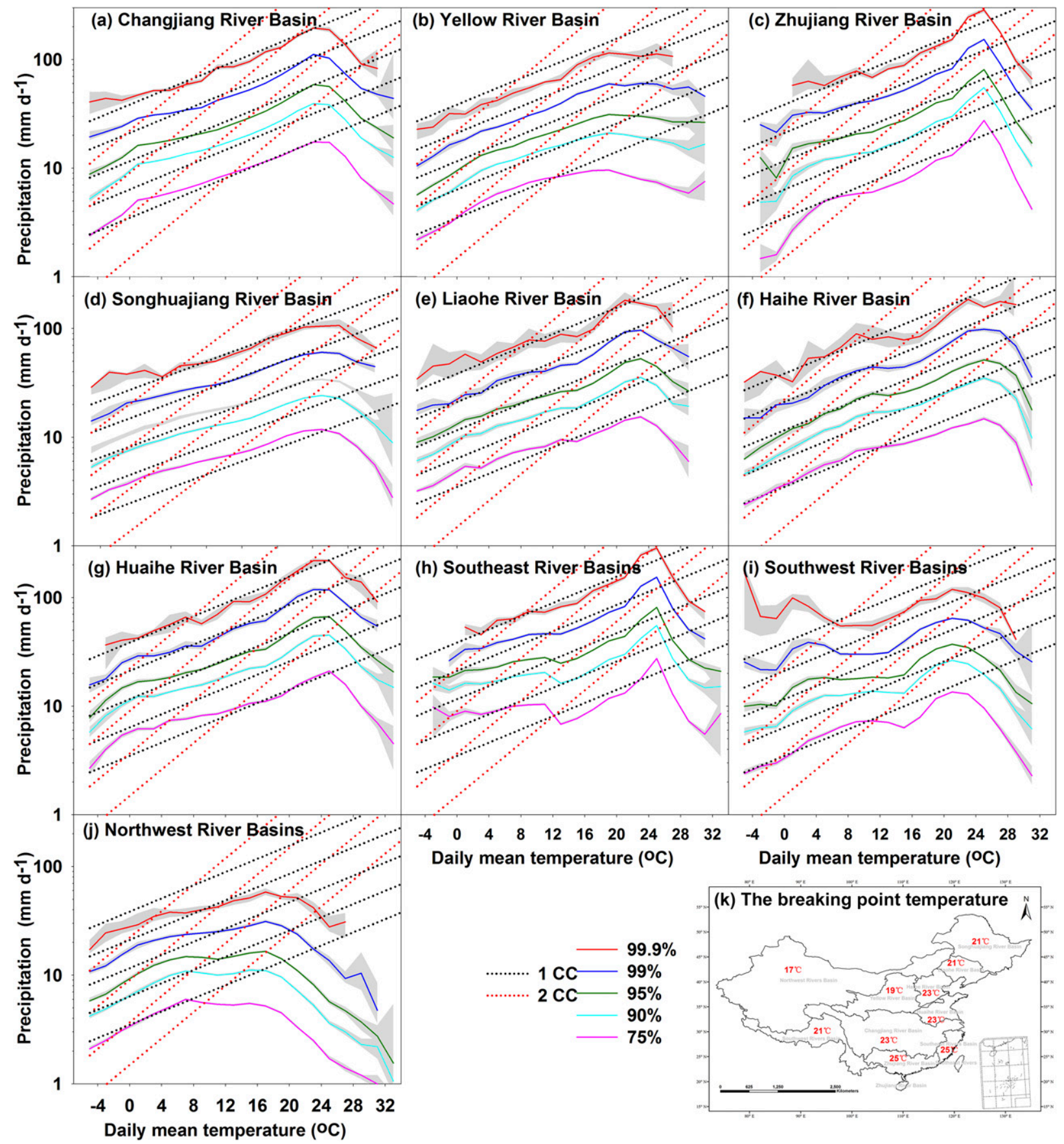

FIG. 3. (a)-(j) Daily precipitation intensity dependence on temperature over 10 river basins in China. (k) The breaking point temperatures of the 10 river basins. Solid color lines represent the 99.9th, 99th, 95th, 90th, and 75th percentiles. Gray bands represent the 90 th percentile confidence intervals estimated by the bootstrap method. Dotted lines represent the 1CC (black) and 2CC (red) relations.

similar scaling behaviors. For $T$ roughly below $25^{\circ} \mathrm{C}$, the different percentiles of $I_{d}$ exhibit a temperature dependency similar to that of the 1CC relation. While $T$ is larger than $25^{\circ} \mathrm{C}, I_{d}$ sharply decreases with an increase in temperature. This positive-negative scaling behavior is consistent with results found in the Amazon and Congo basins, the tropical Pacific, the Indian monsoon region, the U.S. Midwest, central Europe (Wang et al. 2017), Romania (Busuioc et al. 2017), the United Kingdom (Chan et al. 2016), the Mediterranean (Drobinski et al. 2016), Australia (Jones et al. 2010), Japan (Utsumi et al. 2011), and South China (Sun et al. 2013). 
China includes many climatic regions, and the 10 river basins in this study divide and represent these different climate zones. To examine if this scaling behavior is the same in different regions, we analyze the relationships between different percentiles of $I_{d}$ and $T$, which results in similar scaling behaviors among different regions (Fig. 3). When $T$ is lower than the breaking point temperature, $I_{d}$ exhibits a positive $1 \mathrm{CC}$ relation dependence on temperature. Figures $3 \mathrm{~h}-\mathrm{j}$ exhibit a weaker $1 \mathrm{CC}$ scaling behavior. Figures $3 \mathrm{~h}-\mathrm{j}$ contain rivers in the southeast, southwest, and northwest, so each of them has multiple basins, while the other panels contain only one basin (e.g., the rivers of Fig. 3a belong to the Chang River basin). It may be because multiple basins cause unstable relationships between $I_{d}$ and $T$. Figure $3 \mathrm{j}$, which encompasses the northwest region that crosses the Qinghai-Tibetan Plateau, shows a transition from a 1CC scaling to a lower-rated scaling for higher temperature. Schroeer and Kirchengast (2018) also found that temperature sensitivities in the mountainous western region of China were weaker than those in the eastern lowlands of southeastern Austria; this was most likely because moisture was not locally sourced, which led to weaker temperature sensitivities (Schroeer and Kirchengast 2018; Zhang et al. 2017). Each basin has a distinct breaking point, where the breaking point temperature ranges from $17^{\circ}$ to $25^{\circ} \mathrm{C}$ (Fig. 3k), which is consistent with values found in other study areas [e.g., $22^{\circ} \mathrm{C}$ in the United Kingdom (Chan et al. 2016), $20^{\circ} \mathrm{C}$ in the Mediterranean (Drobinski et al. 2016), $26^{\circ} \mathrm{C}$ in Australia (Jones et al. 2010), $25^{\circ} \mathrm{C}$ in South China (Sun et al. 2013), and $18^{\circ} \mathrm{C}$ in Romania (Busuioc et al. 2017)]. More importantly, the breaking point temperature gradually increases from the northwest inland area to the southeast coast, which is consistent with increasing patterns of precipitation, cloud amount, total cloud cover, and Rh across China. This pattern suggests that the breaking point temperature depends on water vapor availability for the occurrence of precipitation and on the distance from the basin to the coast.

\section{2) THE RELATIONSHIP BETWEEN ATMOSPHERIC HUMIDITY AND TEMPERATURE}

Actual vapor pressure is the partial pressure of water vapor at a given temperature. Relative humidity measures how much water the air currently contains as compared to what it would contain if saturated. Evaporation reflects part of the vertical transport of water vapor. All of these are different ways of measuring the amount of water vapor in the atmosphere. We use the abovementioned method to analyze the relationships among $e_{a}, \mathrm{Rh}, E_{\mathrm{pan}}$, and $T$ under the 99.9th, 99th, 95th,

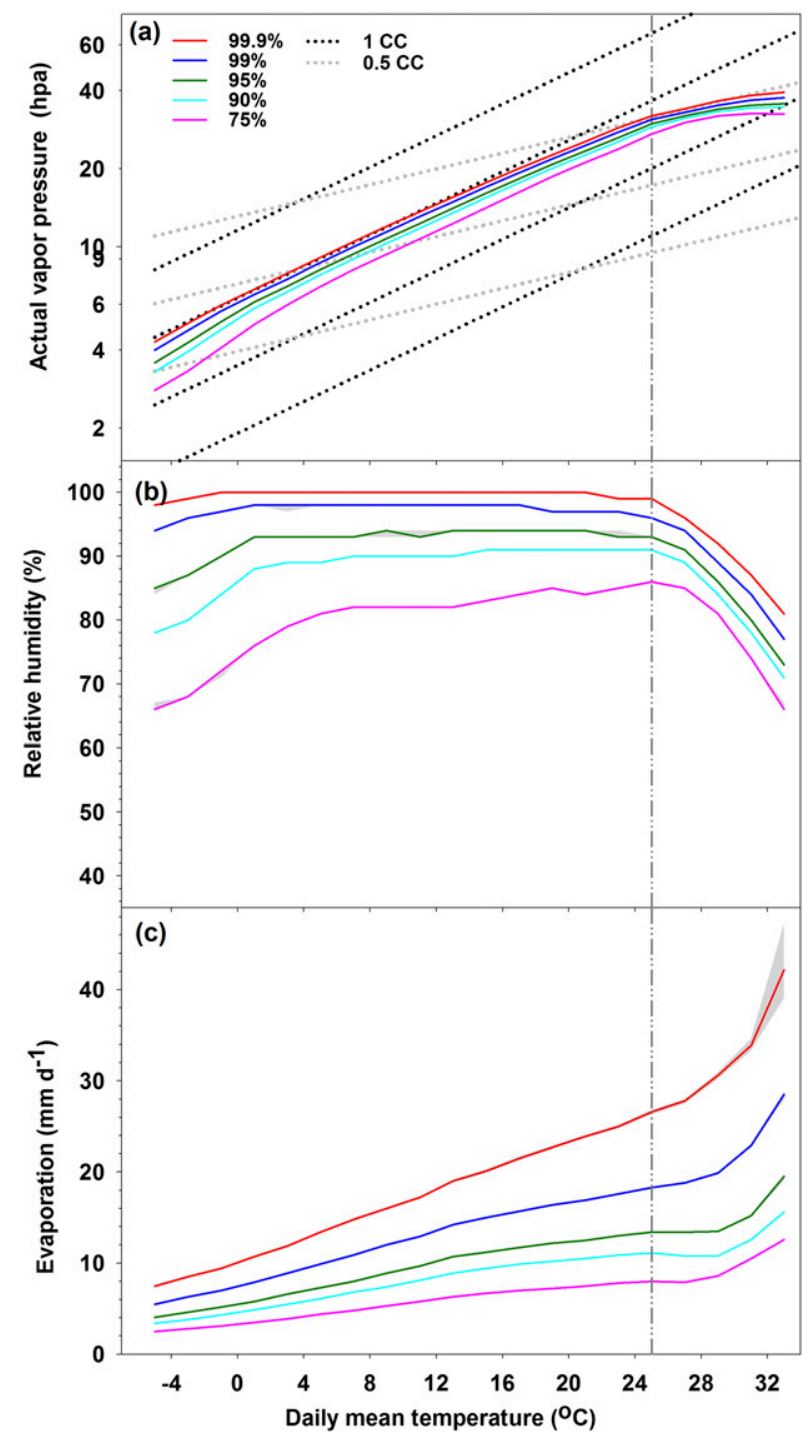

FIG. 4. Temperature relationships with daily precipitation, humidity, and evaporation: (a) $e_{a}$, (b) Rh, and (c) $E_{\text {pan }}$. Solid color lines represent the 99.9th, 99th, 95th, 90th, and 75th percentiles. Gray bands represent the 90th confidence intervals estimated by the bootstrap method. Dotted lines represent the 0.5CC (gray), $1 \mathrm{CC}$ (black), and 2CC (red) relations. The dash-dot line represents the breaking point temperature.

90th, and 75th percentiles. Figure 4a shows different $e_{a}$ percentiles compared with the $\mathrm{CC}$ relation. For lower temperatures, $e_{a}$ is strictly controlled by the CC curve and increases at an approximate rate of $7 \%$ per degree of warming. When $T$ increases to approximately $25^{\circ} \mathrm{C}$, a breaking point occurs. When $T$ continually increases, the temperature dependency of $e_{a}$ transitions from a $1 \mathrm{CC}$ relation to a $0.5 \mathrm{CC}$ (or smaller) relation.

Figure $4 \mathrm{~b}$ shows changes of $\mathrm{Rh}$ for different percentiles. Relative humidity begins to increase as $T$ increases, 


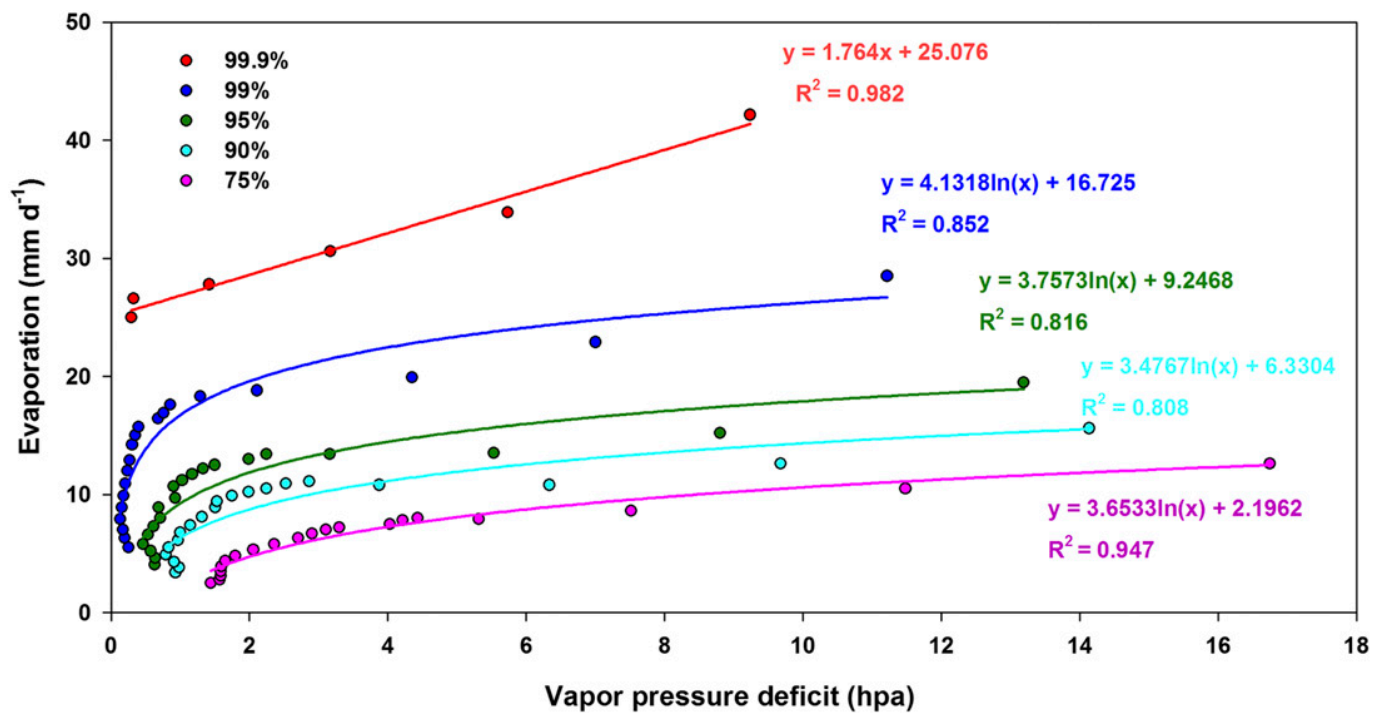

FIG. 5. Percentiles for $E_{\text {pan }}$ vs vapor pressure deficit. The vapor pressure deficit is the difference between $e_{s}$ and $e_{a}$. Scatterplots represent the 99.9th, 99th, 95th, 90th, and 75th percentiles. Solid lines and equations explain the trend lines and fitted formulas of the scatterplots.

then gradually stabilizes at high levels, and sharply decreases when $T$ is greater than $25^{\circ} \mathrm{C}$. Both observations and previous model results have shown similar reductions in $\mathrm{Rh}$ at high temperatures (Jones et al. 2010; Sun et al. 2015; Xiao et al. 2016). This scaling behavior is consistent with that of $e_{a}$ because saturated vapor pressure $e_{s}$ increases exponentially with temperature.

Figure $4 \mathrm{c}$ shows changes of $E_{\mathrm{pan}}$ for different percentiles. Pan evaporation linearly increases with temperature at lower temperatures, and when $T$ is greater than $25^{\circ} \mathrm{C}$, the rate of $E_{\text {pan }}$ rapidly increases. The different percentiles of $E_{\text {pan }}$ show the same trend with $T$ increasing. They are positively correlated with vapor pressure deficits (i.e., the difference between $e_{s}$ and $e_{a}$; Fig. 5), which are consistent with previous research results and related $E_{\text {pan }}$ calculations or models, such as Dalton's (Dalton 1802) and Penman's (Allan et al. 1998) equations of evaporation from water surface.

The relationships among daily $I_{d}, \mathrm{Rh}, e_{a}, E_{\mathrm{pan}}$, and $T$ under the 99.9th, 99th, 95th, 90th, and 75th percentiles are analyzed in the 10 basins. Figure 6 shows the result of the 99.9th percentile, which indicates that the corresponding breaking point temperatures for $I_{d}, \mathrm{Rh}, e_{a}$, and $E_{\mathrm{pan}}$ are identical in the same basin. When $T$ is lower than the breaking point temperature and as $T$ increases precipitation extremes increase, $e_{a}$ increases strictly along the CC curve, $\mathrm{Rh}$ is almost stable at $100 \%$, and the increasing rate of $E_{\mathrm{pan}}$ stabilizes. When $T$ is greater than the breaking point temperature, $I_{d}$ and $\mathrm{Rh}$ decrease rapidly, the increasing rate of $e_{a}$ slows down, and the $E_{\text {pan }}$ rate begins to accelerate. The 99th, 95th, 90th, and 75th percentiles for the 10 basins are shown in Figs. S1-S4 in the online supplemental material.

\section{3) THE RELATIONSHIP BETWEEN DAILY PRECIPITATION EXTREMES AND WATER VAPOR}

To show the direct relationship between $I_{d}$ extremes and water vapor, $I_{d}$ is binned using daily $e_{a}$. The width of each bin is $2 \mathrm{hPa}$. The $e_{a}$ effect at the 99.9th, 99th, 95th, 90th, and 75th percentiles on $I_{d}$ is shown in Fig. 7a (solid color lines). The different percentiles of $I_{d}$ exhibit a positive-negative $e_{a}$ dependency similar to that of the $I_{d} \sim T$ relation (Fig. 2). When $e_{a}$ is lower than the breaking point, $I_{d}$ exhibits a positive linear dependence on $e_{a}$, and the correlation coefficient is not less than 0.98 (Fig. 7b).

Because $e_{s}$ is the maximum partial pressure of water vapor in the air and varies with the temperature of the air and water vapor mixture, $T$ and $e_{a}$ are connected by $e_{\mathrm{s}}$ for studying precipitation extremes. Daily precipitation intensity is binned using daily $e_{s}$, and the width of each bin is $2 \mathrm{hPa}$. The relationship of $I_{d}$ and daily $e_{s}$ at different percentiles is shown in Fig. 7a (dash-dot-dot color lines). The two lines are very similar and have the same trend, and $e_{a}$ is slightly smaller than $e_{s}$ for a given $I_{d}$ under the same percentiles.

The medium gray dashed line in Fig. 7a is the $e_{s}$ value at a given temperature based on the Goff-Gratch equation (Goff and Gratch 1946; Goff 1957), which described how to calculate the $e_{s}$ above a flat, freewater surface as a function of temperature and was recommended for use by the World Meteorological 


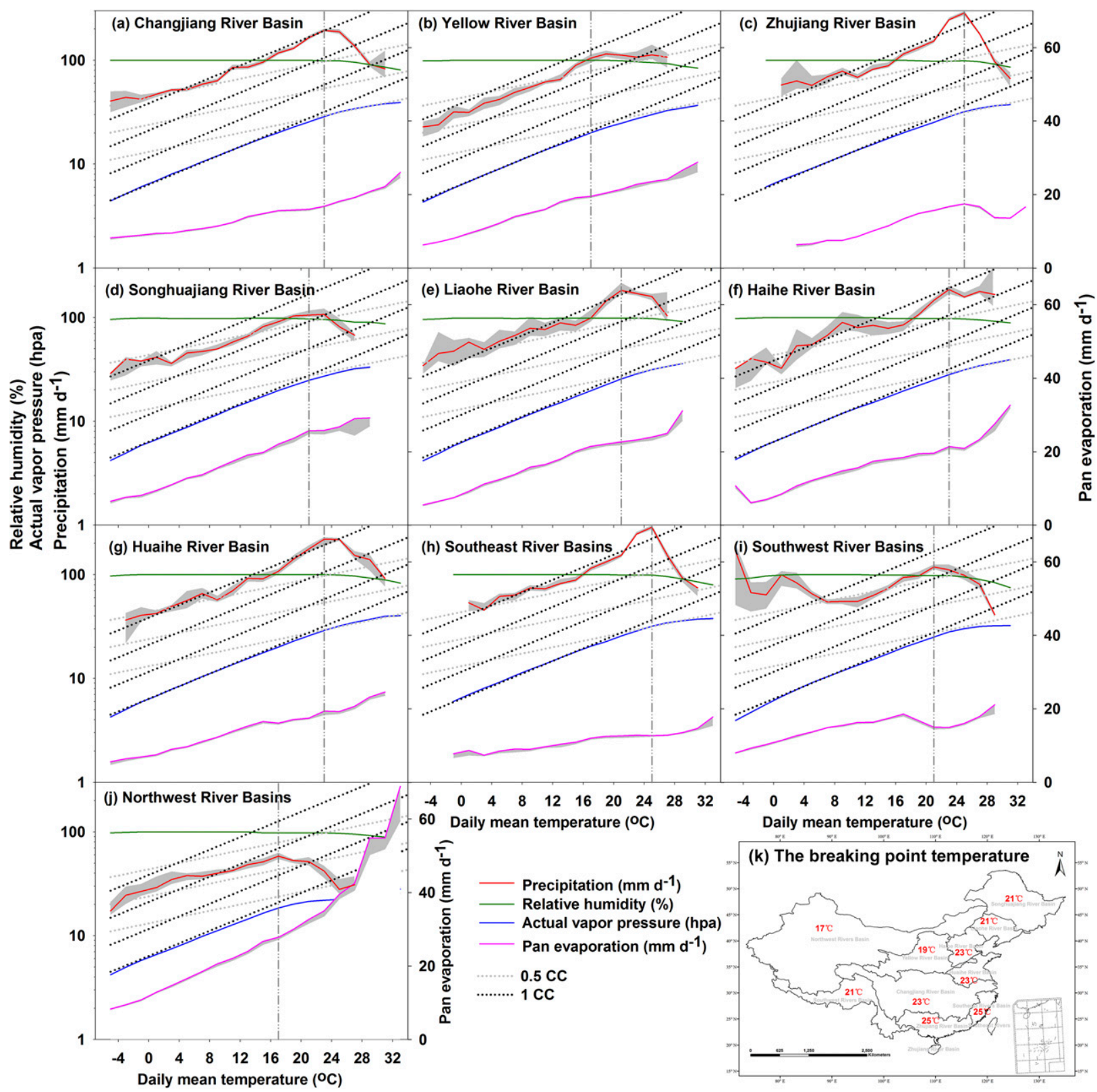

FIG. 6. (a)-(j) The 99.9th percentile for $I_{d}, e_{a}, \mathrm{Rh}$, and $E_{\text {pan }}$ in 10 river basins. (k) The breaking point temperatures for the 10 river basins. Gray bands represent the 90 th percentile confidence intervals estimated by the bootstrap method. Dotted lines represent the $0.5 \mathrm{CC}$ (gray), $1 \mathrm{CC}$ (black), and 2CC (red) relations. The dash-dot line represents the breaking point temperature.

Organization in 1988, with further corrections in 2000. Figure 7a shows that the breaking points for $e_{a}$ and $e_{s}$ are 29.03 and $30.93 \mathrm{hPa}$, and its corresponding breaking point temperature is $24.6^{\circ} \mathrm{C}$, which is close to $25^{\circ} \mathrm{C}$ of the $I_{d} \sim T$ relation (Fig. 2).

Overall, because precipitation extremes tend to occur when the atmosphere is close to saturation at lower temperatures, precipitation extremes increase with warming in proportion to the increase in surface moisture storage capacity, which exponentially increases at a 1CC scaling rate as temperature increases (Singh and O'Gorman 2014; Wang et al. 2017). In this situation, precipitation extremes respond to temperature changes in the absence of moisture limitation. When the temperature is higher than the breaking point temperature (i.e., higher temperature), $e_{a}$ has difficulty maintaining a consistent increasing rate as $e_{s}$ increases exponentially, so higher temperatures result in larger 

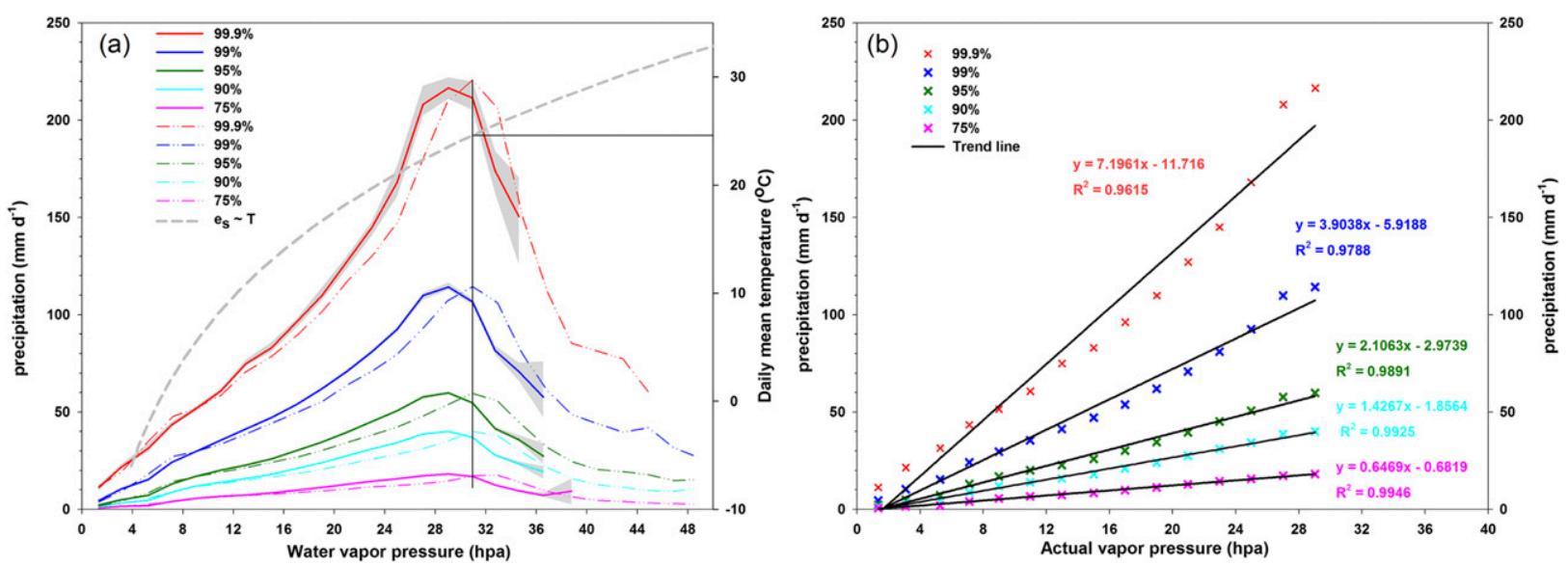

FIG. 7. Daily precipitation intensity $I_{d}$ dependence on $e_{a}$. (a) Different percentiles of $I_{d} \mathrm{vs} e_{a}$ (solid color lines) and $e_{s}$ (dash-dot-dot color lines). The medium gray dash line is the $e_{s}$ value at a given $T$. Gray bands represent the 90 th percentile confidence intervals estimated by the bootstrap method. (b) Different percentiles of $I_{d}$ vs $e_{a}$ when $e_{a}$ is lower than the breaking point. The color equations explain the trend lines and fitted formulas of the corresponding color scatterplots.

vapor pressure deficits, which leads to a sharp increase in precipitation extremes. And similar scaling behaviors are obtained in 10 river basins over China, where the breaking point temperature depends on the distance from the coast to the basin and increases from $17^{\circ} \mathrm{C}$ along the northwest inland area to $25^{\circ} \mathrm{C}$ along the southeast coast. This pattern suggests that insufficient moisture availability inhibits the development of precipitation extremes.

\section{$b$. The dependence of hourly precipitation extremes on temperature and atmospheric humidity}

\section{1) THE RELATIONSHIP BETWEEN HOURLY PRECIPITATION EXTREMES AND TEMPERATURE}

Figure 8 shows the 99.9th, 99th, 95th, 90th, and 75th percentiles for hourly precipitation intensity $I_{h}$ under $T$, daily maximum air temperature $T_{d \max }$, minimum air temperature $T_{d \min }$ temperature at $2-\mathrm{m}$ height in a day, and $T_{h}$. The scaling behaviors among $I_{h}$ and $T$ (Fig. 8a), $T_{d \max }$ (Fig. 8c), $T_{d \min }$ (Fig. 8d), and $T_{h}$ (Fig. 8b) are generally similar. Hourly precipitation intensity increases at lower temperatures, then fluctuates from positive to negative under temperatures exceeding the breaking point temperature, indicating scaling similar to that for daily temperatures. The corresponding breaking point temperatures are approximately $23^{\circ}-25^{\circ} \mathrm{C}$ for $T$, $T_{d \min }$, and $T_{h}$, but temperatures are higher for $T_{d \max }$. However, the increasing rates of $I_{d}$ and $I_{h}$ are different when the temperature is lower than the breaking point temperature. Daily precipitation intensity exhibits a temperature dependency similar to the $1 \mathrm{CC}$ rate. Hourly precipitation intensity exhibits an increasing rate similar to the $1 \mathrm{CC}$ relation at lower temperatures, which increases to a $2 \mathrm{CC}$ relation at higher temperatures. This scaling behavior is more distinct for higher percentiles (i.e., 99.9th and 99th) and weaker for lower percentiles (75th and 90th). The corresponding $T$ transitions from $1 \mathrm{CC}$ to $2 \mathrm{CC}$ are approximately $13^{\circ} \mathrm{C}$ for the 99.9 th and 99th percentiles and $17^{\circ} \mathrm{C}$ for the 95 th percentile. The corresponding $T_{h}$ transitions are approximately $11^{\circ} \mathrm{C}$ for the 99.9th and 99th percentiles and $13^{\circ} \mathrm{C}$ for the 95th percentile. This transition behavior for $I_{h}$ from a $1 \mathrm{CC}$ to $2 \mathrm{CC}$ scaling (when $T$ exceeds approximately $12^{\circ} \mathrm{C}$ ) has been identified (Haerter and Berg 2009; Lenderink and Meijgaard 2008). And some results imply that the convective field or systems drive this scaling based on cloud observations (Berg et al. 2013), the presence of lightning (Molnar et al. 2015), or simulations (Meredith et al. 2015; Moseley et al. 2016). Because the atmospheric temperature at $2 \mathrm{~m}$ is different from the temperature at the height of clouds, this difference in temperature may also affect extreme precipitation analysis. Atmospheric humidity (Trenberth et al. 2003; Liu et al. 2009), precipitation type (Berg et al. 2013) and duration (Utsumi et al. 2011; Sun et al. 2013), cloud and precipitation microphysics (Singh and O'Gorman 2014), El Niño events (Allen and Luptowitz 2017), orography (Drobinski et al. 2016), and anthropogenic aerosols and greenhouse gases (Chen et al. 2011; Min et al. 2011) have been thought to influence the scaling behaviors of precipitation extremes at higher temperatures or for short durations.

\section{2) THE RELATIONSHIP BETWEEN HOURLY ATMOSPHERIC HUMIDITY AND TEMPERATURE}

Figure 9 shows the relationship of temperature to $e_{a}$, $\mathrm{Rh}$, and $q$ under the 99.9th, 99th, 95th, 90th, and 75th 

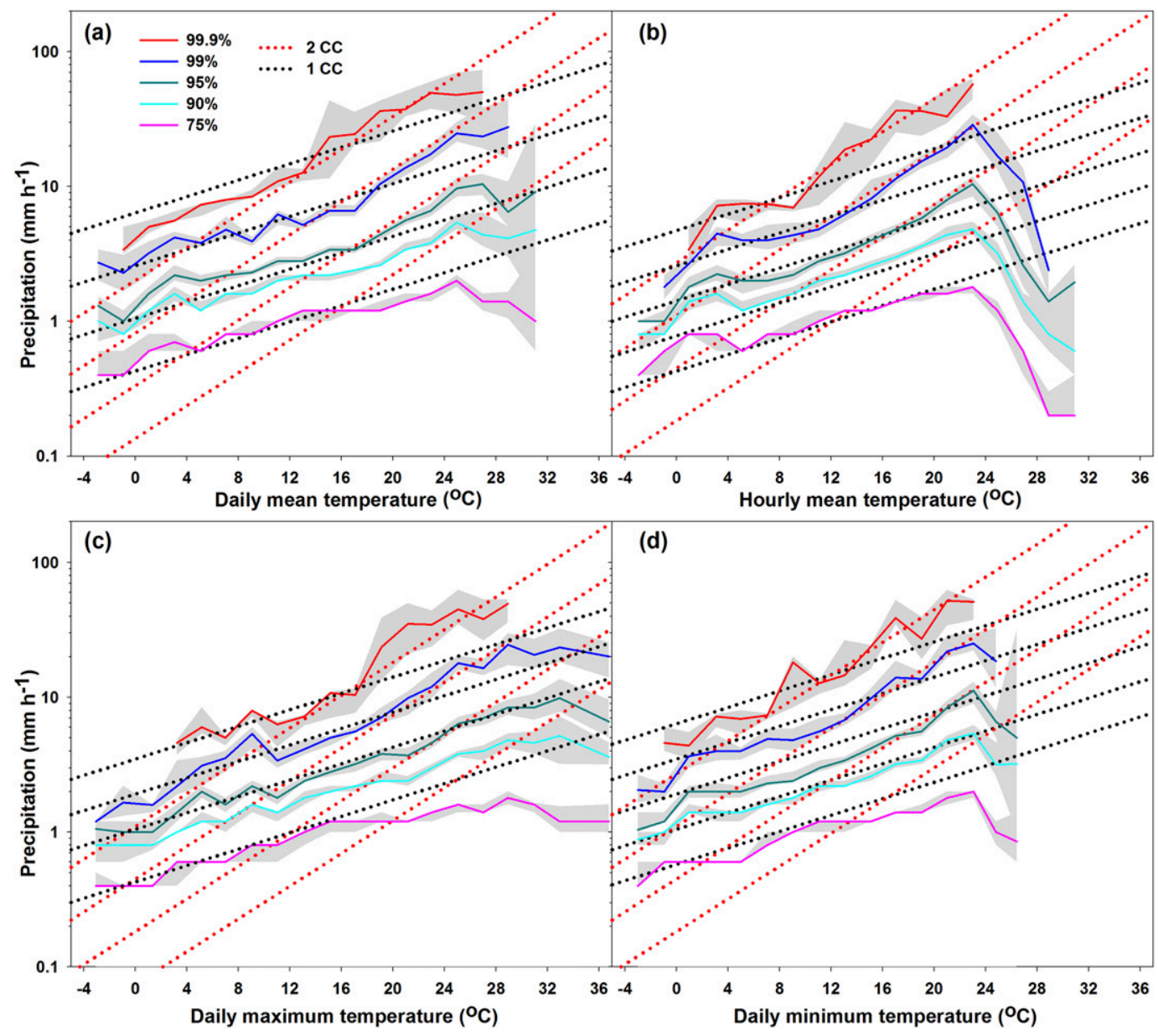

FIG. 8. Hourly precipitation intensity dependence on temperature. (a) Observed 1-h precipitation intensity vs $T$, (b) $T_{h}$, (c) $T_{d \max }$, and (d) $T_{d \min }$. Solid color lines represent the 99.9th, 99th, 95th, 90th, and 75th percentiles. Gray bands represent the 90 th percentile confidence intervals estimated by the bootstrap method. Dotted lines represent the 1CC (black) and 2CC (red) relations.

percentiles. Figures $9 \mathrm{a}-\mathrm{c}$ and Figs. $9 \mathrm{~d}-\mathrm{f}$ show the results for $T$ and $T_{h}$, respectively. The scaling behaviors of each variable are similar for $T$ and $T_{h}$, while the fluctuation in $T_{h}$ scaling is stronger because $T_{h}$ is mainly controlled by boundary layer processes and radiation (Lenderink and Meijgaard 2008). When the temperature is lower than the breaking point temperature, $e_{a}$ exhibits a temperature dependency similar to the $1 \mathrm{CC}$ rate. $\mathrm{Rh}$ begins to increase as $T$ increases, then gradually stabilizes. The $q$ exponentially increases first, then transits toward a linear increase. Overall transition temperatures $\left(13^{\circ} \mathrm{C}\right.$ for the 99.9th and 99th daily percentiles and $17^{\circ} \mathrm{C}$ for the 95 th percentile) are in agreement with those of $T_{h}$, which are approximately $11^{\circ} \mathrm{C}$ for the 99.9 th and 99 th percentiles and $13^{\circ} \mathrm{C}$ for the 95 th percentile. This scaling behavior is weaker for lower percentiles, where the transition temperature is higher. The breaking point temperature is approximately $25^{\circ} \mathrm{C}$ for $T$ and $23^{\circ} \mathrm{C}$ for $T_{h}$. When the temperature is greater than the breaking point temperature, $e_{a}$ and $q$ slightly increase or maintain stability, and $\mathrm{Rh}$ decreases sharply with an increase in temperature.

Hourly intensity is binned using hourly $q$ data, and the width of each bin is $2 \mathrm{~g} \mathrm{~kg}^{-1}$. The $q$ and $T$ effect at the 99.9th, 99th, 95th, 90th, and 75th percentiles on $I_{h}$ are compared in Fig. 10. The two lines under the same percentile are very similar and have the same trend.

Both daily and hourly results showed that temperature changes in water vapor-related variables, precipitation, $e_{a}, q, \mathrm{Rh}$, and $E_{\mathrm{pan}}$ are similar, especially the breaking points. These variables also have a very strong basis for observations. When the temperature is lower, $e_{a}$ is strictly controlled by the CC curve; 

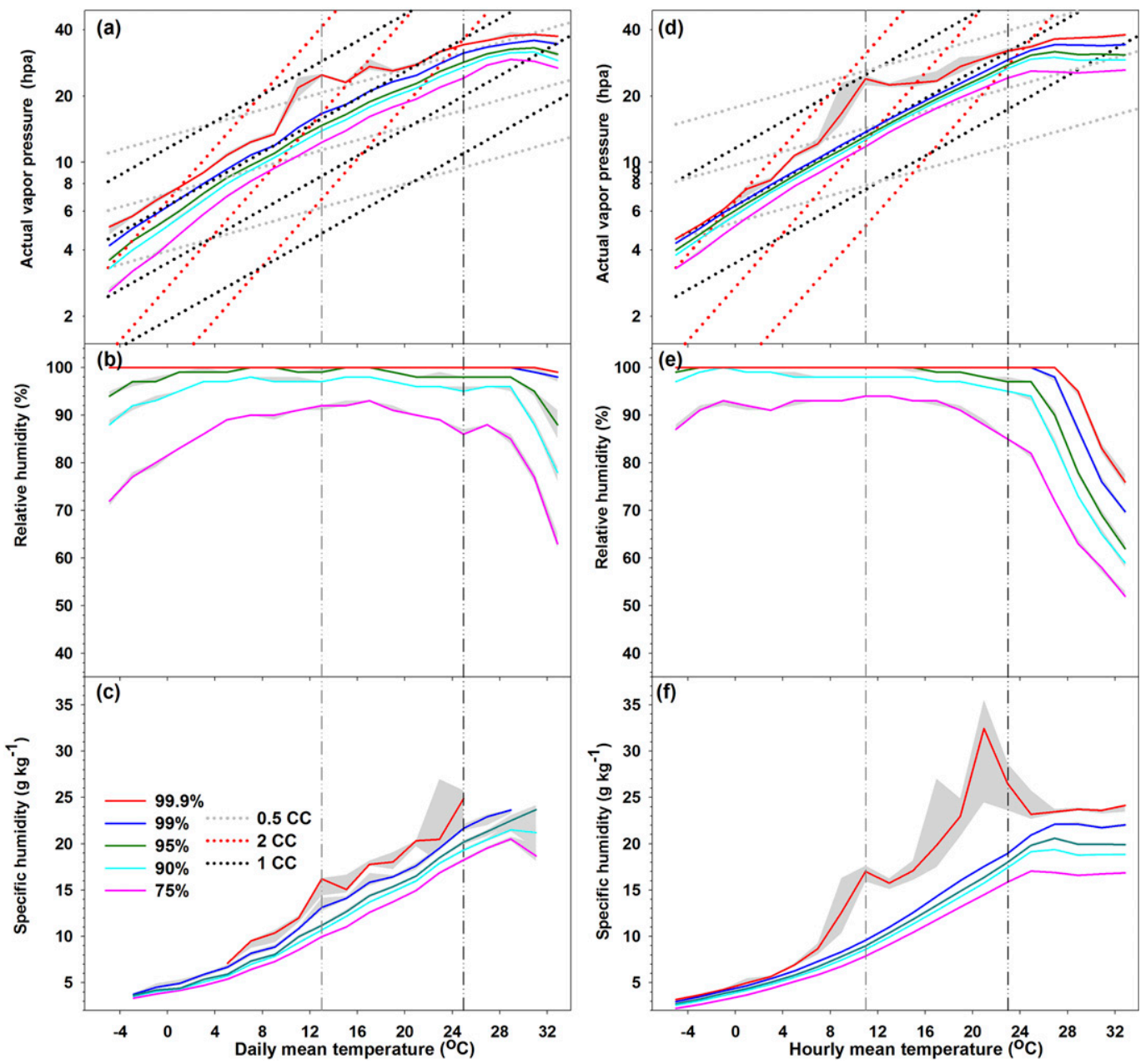

FIG. 9. Relationships among temperature, hourly precipitation, and humidity for (left) $T$ and (right) $T_{h}$, with (a),(d) $e_{a}$, (b),(e) Rh, and (c),(f) $q$. Solid color lines represent the 99.9th, 99th, 95th, 90th, and 75th percentiles. Gray bands represent the 90th percentile confidence intervals estimated by the bootstrap method. Dotted lines represent the $0.5 \mathrm{CC}$ (gray), 1CC (black), and 2CC (red) relations. The dash-dot line (black) represents the breaking point temperature, and the dash-dot line (gray) represents temperature that increases the rates of 99.9th and 99th percentile precipitation values that transitioned from $1 \mathrm{CC}$ to $2 \mathrm{CC}$.

$\mathrm{Rh}$ increases first, then stabilizes; precipitation extremes increase continuously and exhibit a positive dependence on $e_{a}$ or $q$. In this situation, $e_{a}$ is approximately equal to $e_{s}$, and precipitation extremes result from temperatures with sufficient moisture capacity. However, for higher temperatures, $e_{a}$ slightly decreases or remains stable and $\mathrm{Rh}$ sharply decreases, which leads to larger vapor pressure deficits, and precipitation extremes sharply decrease. In this situation, precipitation extremes result from high temperatures with insufficient moisture capacity. Both daily and hourly precipitation extremes result from humidity control at the same temperature. It should be pointed out that sufficient moisture capacity and insufficient moisture capacity are both at an atmospheric temperature of
$2 \mathrm{~m}$, which is different from the temperature at the height of clouds.

\section{Conclusions}

Precipitation extreme events become more intense in a warmer climate. Based on data for 16325552 days at 702 meteorological stations over China during 19512014, we find that when the temperature is lower than $25^{\circ} \mathrm{C}$, precipitation extremes exhibit a temperature dependency similar to the $1 \mathrm{CC}$ relation, which decreases sharply with temperatures greater than $25^{\circ} \mathrm{C}$. A similar scaling behavior is obtained in 10 river basins over China, where the temperature breaking point gradually increases from northwest $\left(17^{\circ} \mathrm{C}\right)$ to southeast $\left(25^{\circ} \mathrm{C}\right)$. 


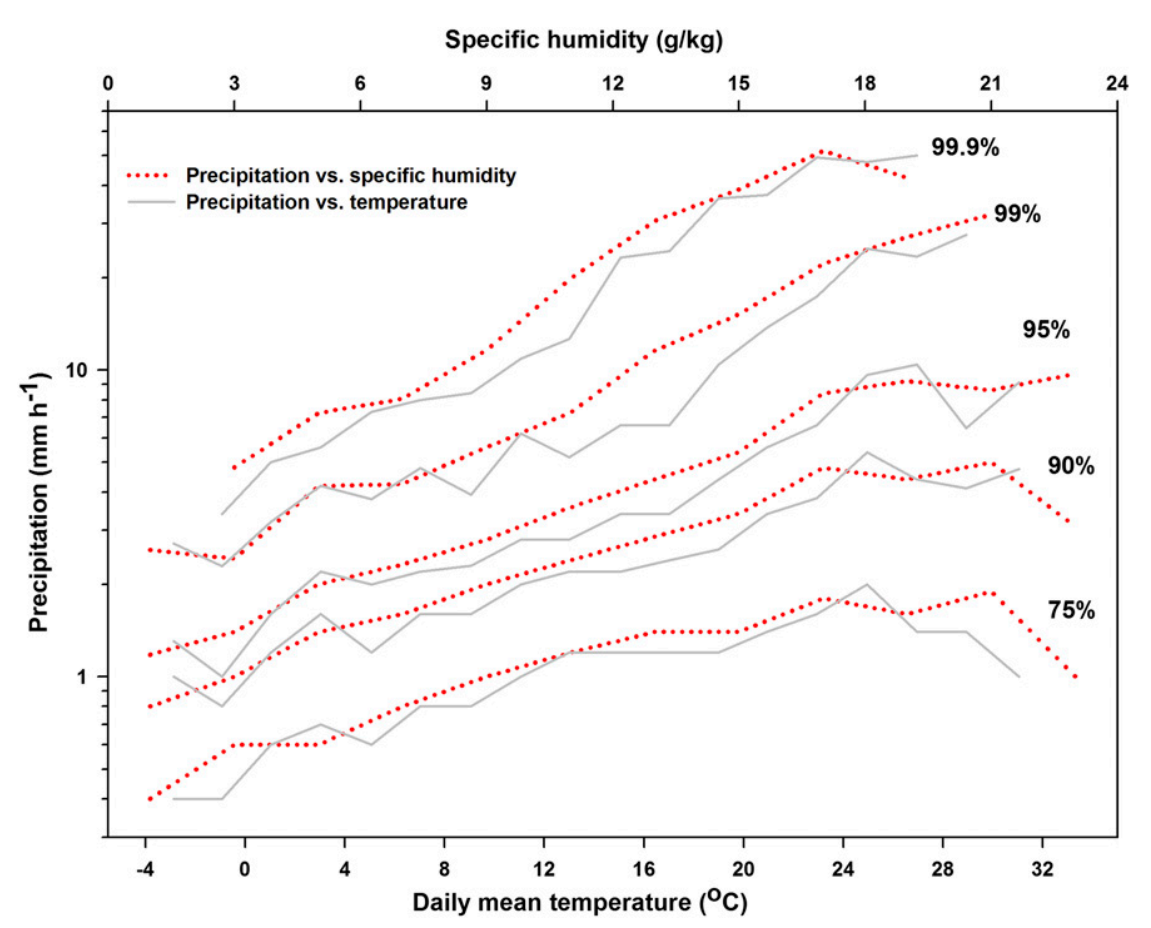

FIG. 10. Different percentiles of $I_{h}$ vs $q$ and $T$.

This behavior suggests that the breaking point temperature depends on water vapor availability for the occurrence of precipitation and on the basin distance from the coast.

Based on data for $592841 \mathrm{~h}$ at eight meteorological stations over China during 2000-15, we find that the breaking point temperature is also $25^{\circ} \mathrm{C}$. When the temperature is lower than $13^{\circ} \mathrm{C}$, precipitation extremes increase at a rate similar to the $1 \mathrm{CC}$ relation; this rate increases to a $2 \mathrm{CC}$ relation for $13^{\circ}-25^{\circ} \mathrm{C}$ temperatures, then scaling decreases sharply with temperatures greater than $25^{\circ} \mathrm{C}$.

We use the same scaling method to analyze the dependence of daily and hourly atmospheric humidity on temperature by analyzing relationships among $\mathrm{Rh}, e_{a}$, $q$, and $E_{\mathrm{pan}}$. We find that both daily and hourly temperature changes for extremes of $e_{a}, q, \mathrm{Rh}$, and $E_{\mathrm{pan}}$ are accordant with that of precipitation extremes. Then we use the same method to analyze the daily and hourly precipitation extremes on atmospheric humidity by analyzing relationships between $I_{d}$ and $e_{a}$ and $I_{h}$ and $q$. When $e_{a}$ is lower than the breaking point, $I_{d}$ exhibits a positive linear dependence on $e_{a}$, the correlation coefficient is not less than 0.98 , and its corresponding breaking point temperature is $24.6^{\circ} \mathrm{C}$. The $q$ and $T$ effect on $I_{h}$ are very similar under the same percentile. Both daily and hourly precipitation extremes result from humidity control at the same temperature.
Acknowledgments. This work was supported by the National Key Research and Development Program of China (2016YFA0602402), the National Natural Science Foundation of China (41601035), the Key Programs of the Chinese Academy of Sciences (ZDRWZS-2017-3-1), the Chinese Academy of Sciences (CAS) Pioneer Hundred Talents Program, the CPSF-CAS Joint Foundation for Excellent Postdoctoral Fellows, Institute of Ecology and Geography, and the Chinese Academy of Sciences. The authors thank the CMDC (http://data.cma.cn) and the CERN (http://www. cnern.org.cn), including the ASA, CWA, LCA, YGA, NMD, SPD, GGF, and QIA stations, for providing data support.

\section{APPENDIX}

\section{The Abbreviation of Variables in the Manuscript}

CC Clausius-Clapeyron

$e_{a} \quad$ Actual vapor pressure (hPa)

$e_{s} \quad$ Saturated vapor pressure $(\mathrm{hPa})$

$E_{\text {pan }} \quad$ Pan evaporation (mm day ${ }^{-1}$ )

$I_{d} \quad$ Daily precipitation intensity $\left(\mathrm{mm} \mathrm{day}^{-1}\right)$

$I_{h} \quad$ Hourly precipitation intensity $\left(\mathrm{mm} \mathrm{day}^{-1}\right)$

$q \quad$ Specific humidity $\left(\mathrm{g} \mathrm{kg}^{-1}\right)$

$\mathrm{Rh} \quad$ Relative humidity (\%) 
$T \quad$ Daily mean temperature at 2 -m height $\left({ }^{\circ} \mathrm{C}\right)$

$T_{h} \quad$ Hourly mean temperature at $2-\mathrm{m}$ height $\left({ }^{\circ} \mathrm{C}\right)$

$T_{d \max }$ Daily maximum air temperature at 2-m height in a day (2000-2000 Chinese standard time; $\left.{ }^{\circ} \mathrm{C}\right)$

$T_{d \text { min }} \quad$ Daily minimum air temperature at $2-\mathrm{m}$ height in a day (2000-2000 Chinese standard time; $\left.{ }^{\circ} \mathrm{C}\right)$

\section{REFERENCES}

Allan, R. G., L. S. Pereira, D. Raes, and M. Smith, 1998: Crop evapotranspiration: Guidelines for computing crop water requirements. FAO Irrigation and Drainage Paper 56, 300 pp.

Allen, R. J., and R. Luptowitz, 2017: El Niño-like teleconnection increases California precipitation in response to warming. Nat. Commun., 8, 16055, https://doi.org/10.1038/ncomms16055.

Allan, R. P., and B. J. Soden, 2008: Atmospheric warming and the amplification of precipitation extremes. Science, 321, 14811484, https://doi.org/10.1126/science.1160787.

Bao, J., S. C. Sherwood, L. V. Alexander, and J. P. Evans, 2017: Future increases in extreme precipitation exceed observed scaling rates. Nat. Climate Change, 7, 128-132, https://doi.org/ 10.1038/nclimate3201.

Barbero, R., S. Westra, G. Lenderink, and H. J. Fowler, 2017: Temperature-extreme precipitation scaling: A two-way causality? Int. J. Climatol., 38, 1274-1279, https://doi.org/10.1002/ joc.5370.

Berg, P., C. Moseley, and J. O. Haerter, 2013: Strong increase in convective precipitation in response to higher temperatures. Nat. Geosci., 6, 181-185, https://doi.org/10.1038/ ngeo1731.

Busuioc, A., M. Baciu, T. Breza, A. Dumitrescu, C. Stoica, and N. Baghina, 2017: Changes in intensity of high temporal resolution precipitation extremes in Romania: Implications of Clausius-Clapeyron scaling. Climate Res., 72, 239-249, https:// doi.org/10.3354/cr01469.

Chan, S. C., E. J. Kendon, N. M. Roberts, H. J. Fowler, and S. Blenkinsop, 2016: Downturn in scaling of UK extreme rainfall with temperature for future hottest days. Nat. Geosci., 9, 24-28, https://doi.org/10.1038/ngeo2596.

Chen, G., Y. Ming, N. D. Singer, and J. Lu, 2011: Testing the Clausius-Clapeyron constraint on the aerosol-induced changes in mean and extreme precipitation. Geophys. Res. Lett., 38, L04807, https://doi.org/10.1029/2010GL046435.

CMDC, 2012: Dataset of daily climate data from Chinese surface stations for global exchange, version 3.0. CMDC, accessed 4 August 2012, http://data.cma.cn/data/cdcdetail/dataCode/SURF_ CLI_CHN MUL DAY V3.0.html.

Dalton, J., 1802: Experimental essays on the constitution of mixed gases: On the force of steam or vapor from water or other liquids in different temperatures, both in a Torricelli vacuum and in air, on evaporation, and on expansion of gases by heat Manchester Lit. Philos. Soc., 5, 536-602.

Donat, M. G., A. L. Lowry, L. V. Alexander, P. A. O'Gorman, and N. Maher, 2016: More extreme precipitation in the world's dry and wet regions. Nat. Climate Change, 6, 508-513, https:// doi.org/10.1038/nclimate2941; Corrigendum, 7, 154-158, https:// doi.org/10.1038/nclimate3160.

Drobinski, P., B. Alonzo, S. Bastin, N. Da Silva, and C. Muller, 2016: Scaling of precipitation extremes with temperature in the French Mediterranean region: What explains the hook shape? J. Geophys. Res. Atmos., 121, 3100-3119, https://doi.org/ 10.1002/2015JD023497.
Fischer, E. M., and R. Knutti, 2016: Observed heavy precipitation increase confirms theory and early models. Nat. Climate Change, 6, 986-992, https://doi.org/10.1038/nclimate3110.

Goff, J. A., 1957: Saturation pressure of water on the new Kelvin temperature scale. Transactions of the American Society of Heating and Ventilating Engineers, Murray Bay, Quebec, Canada, American Society of Heating and Ventilating Engineers, 347-354.

—, and S. Gratch, 1946: Low-pressure properties of water from -160 to $212^{\circ} \mathrm{F}$. Transactions of the American Society of Heating and Ventilating Engineers, New York, NY, American Society of Heating and Ventilating Engineers, 95-122.

Haerter, J. O., and P. Berg, 2009: Unexpected rise in extreme precipitation caused by a shift in rain type? Nat. Geosci., 2, 372-373, https://doi.org/10.1038/ngeo523.

Huang, D., Y. Peiwen, L. Gaoping, and Z. Jian, 2017: Relationship between precipitation extremes with temperature in the warm season in Anhui Province (in Chinese). Climatic Environ. Res., 22, 623-632.

Jones, R. H., S. Westra, and A. Sharma, 2010: Observed relationships between extreme sub-daily precipitation, surface temperature, and relative humidity. Geophys. Res. Lett., 37, L22805, https://doi.org/10.1029/2010GL045081.

Lenderink, G., and E. V. Meijgaard, 2008: Increase in hourly precipitation extremes beyond expectations from temperature changes. Nat. Geosci., 1, 511-514, https://doi.org/10.1038/ ngeo262.

Liu, S. C., C. Fu, C.-J. Shiu, J.-P. Chen, and F. Wu, 2009: Temperature dependence of global precipitation extremes. Geophys. Res. Lett., 36, L17702, https://doi.org/10.1029/2009GL040218.

Lu, Y., X. Zhang, S. Chen, and H. Sun, 2016: Changes in water use efficiency and water footprint in grain production over the past 35 years: A case study in the North China Plain. J. Cleaner Prod., 116, 71-79, https://doi.org/10.1016/ j.jclepro.2016.01.008.

Meredith, E. P., V. A. Semenov, D. Maraun, W. Park, and A. V. Chernokulsky, 2015: Crucial role of Black Sea warming in amplifying the 2012 Krymsk precipitation extreme. Nat. Geosci., 8, 615-620, https://doi.org/10.1038/ngeo2483.

Min, S.-K., X. Zhang, F. W. Zwiers, and G. C. Hegerl, 2011: Human contribution to more-intense precipitation extremes. Nature, 470, 378-381, https://doi.org/10.1038/nature09763; Corrigendum, 498, 526, https://doi.org/10.1038/nature12197.

Molnar, P., S. Fatichi, L. Gaál, J. Szolgay, and P. Burlando, 2015: Storm type effects on super Clausius-Clapeyron scaling of intense rainstorm properties with air temperature. Hydrol. Earth Syst. Sci., 19, 1753-1766, https://doi.org/10.5194/ hess-19-1753-2015.

Moseley, C., C. Hohenegger, P. Berg, and J. O. Haerter, 2016: Intensification of convective extremes driven by cloud-cloud interaction. Nat. Geosci., 9, 748-754, https://doi.org/10.1038/ngeo2789.

Park, I. H., and S. K. Min, 2017: Role of convective precipitation in the relationship between subdaily extreme precipitation and temperature. J. Climate., 30, 9527-9537, https://doi.org/ 10.1175/JCLI-D-17-0075.1.

Prein, A. F., R. M. Rasmussen, K. Ikeda, C. Liu, M. P. Clark, and G. J. Holland, 2017: The future intensification of hourly precipitation extremes. Nat. Climate Change, 7, 48-52, https:// doi.org/10.1038/nclimate3168.

Schroeer, K., and G. Kirchengast, 2018: Sensitivity of extreme precipitation to temperature: The variability of scaling factors from a regional to local perspective. Climate Dyn., 11-12, 3981-3994, https://doi.org/10.1007/s00382-017-3857-9. 
Singh, M. S., and P. A. O'Gorman, 2014: Influence of microphysics on the scaling of precipitation extremes with temperature. Geophys. Res. Lett., 41, 6037-6044, https://doi.org/10.1002/ 2014 GL061222.

Singleton, A., and R. Toumi, 2013: Super-Clausius-Clapeyron scaling of rainfall in a model squall line. Quart. J. Roy. Meteor. Soc., 139, 334-339, https://doi.org/10.1002/qj.1919.

Sun, W., J. Li, and R. Yu, 2013: Corresponding relation between warm season precipitation extremes and surface air temperature in South China. Adv. Climate Change Res., 4, 160-165, https://doi.org/10.3724/SP.J.1248.2013.160.

__ W. Yuan, J. Li, and R. Yu, 2015: Correlation between peak intensity of extreme short-duration rainfall and humidity and surface air temperature in southeast coast of China (in Chinese). J. Trop. Meteor., 21, 276-284, https://doi.org/ 10.16555/j.1006-8775.2015.03.007.

Trenberth, K. E., A. Dai, R. M. Rasmussen, and D. B. Parsons, 2003: The changing character of precipitation. Bull. Amer. Meteor. Soc., 84, 1205-1217, https://doi.org/10.1175/ BAMS-84-9-1205.

Utsumi, N., S. Seto, S. Kanae, E. E. Maeda, and T. Oki, 2011: Does higher surface temperature intensify extreme precipitation? Geophys. Res. Lett., 38, L16708, https://doi.org/10.1029/ 2011 GL048426.

Wang, G., D. Wang, K. E. Trenberth, A. Erfanian, M. Yu, M. G. Bosilovich, and D. T. Parr, 2017: The peak structure and future changes of the relationships between extreme precipitation and temperature. Nat. Climate Change, 7, 268274, https://doi.org/10.1038/nclimate3239.

Wang, Y., X. Zhang, X. Zhang, L. Shao, S. Chen, and X. Liu, 2016: Soil water regime affecting correlation of carbon isotope discrimination with yield and water-use efficiency of winter wheat. Crop Sci., 56, 760-772, https://doi.org/10.2135/ cropsci2014.11.0793.

Westra, S., and Coauthors, 2014: Future changes to the intensity and frequency of short-duration extreme rainfall. Rev. Geophys., 52, 522-555, https://doi.org/10.1002/2014RG000464.

Xiao, C., P. Wu, L. Zhang, and L. Song, 2016: Robust increase in extreme summer rainfall intensity during the past four decades observed in China. Sci. Rep., 6, 38506, https://doi.org/10.1038/ srep38506.

Ye, H., E. J. Fetzer, S. Wong, A. Behrangi, D. Yang, and B. H. Lambrigtson, 2015: Increasing atmospheric water vapor and higher daily precipitation intensity over northern Eurasia. Geophys. Res. Lett., 42, 9404-9410, https://doi.org/10.1002/2015GL066104.

Zhang, D.-H., X.-R. Li, F. Zhang, Z.-S. Zhang, and Y.-L. Chen, 2016: Effects of rainfall intensity and intermittency on woody vegetation cover and deep soil moisture in dryland ecosystems. J. Hydrol., 543B, 270-282, https://doi.org/10.1016/ j.jhydrol.2016.10.003.

Zhang, X., F. W. Zwiers, G. Li, H. Wan, and A. J. Cannon, 2017: Complexity in estimating past and future extreme shortduration rainfall. Nat. Geosci., 10, 255-259, https://doi.org/ 10.1038/ngeo2911. 